\title{
IDENTIFICAÇÃO DE ISOLADOS DE Azospirillum amazonense ASSOCIADOS A Brachiaria Spp., EM DIFERENTES ÉPOCAS E CONDIÇÕES DE CULTIVO E PRODUÇÃO DE FITORMÔNIO PELA BACTÉRIA ${ }^{(\mathfrak{1})}$
}

\author{
F. B. REIS J UNIOR ${ }^{(2)}$, M. F. SILVA ${ }^{(3)}$, K. R. S. TEIXEIRA(3), \\ S. URQUIAGA ${ }^{(3)} \&$ V. M. REIS(3)
}

\begin{abstract}
RESUMO
Existem evidências de que pastagens formadas por algumas espécies do gênero Brachiaria poderiam beneficiar-se com o processo de fixação biológica do nitrogênio atmosférico (FBN), garantindo a estas pastagens maior longevidade. Dentre as bactérias diazotróficas encontradas em associação com estas gramíneas forrageiras, destaca-se a espécie Azospirillum amazonense. Neste trabalho, objetivou-se verificar a influência da espécie de B rachiaria, manejo da pastagem e sazonalidade sobre as populações de $A$. amazonenseassociadas às raízes destas plantas. Diferentes pastagens (B. humi di cola, B. decumbens e B. brizantha) foram introduzidas em regiões do ecossistema Cerrado e de Mata Atlântica. Foram avaliados dois sistemas de manejo com diferentes taxas de lotação, e as coletas foram realizadas em diferentes épocas do ano. As populações de A. amazonense foram quantificadas e a identidade dos isolados confirmada, assim como sua capacidade de produção de fitormônios ti po AIA (ácido 3-indol acético) em meio de cultivo. I solados de A. amazonenseforam obtidos a partir de amostras de raízes das três espécies de Brachiaria avaliadas. Estimativas das populações desta bactéria variaram de $10^{3}-10^{7}$ células $\mathrm{g}^{-1}$ de raízes. E $\mathrm{m}$ amostras do ecossistema Cerrado, a época de coleta apresentou efeito significativo sobre a população destas bactérias. Os dados da região de Mata Atlântica mostraram que plantas de Brachiaria de diferentes espécies e pastagens sob diferentes taxas de lotação podem apresentar números populacionais distintos associados às suas raízes. A técnica de análise de restrição do DNA ribossomal amplificado (ARDRA) confirmou a identidade de todos os isolados avaliados. Estes isolados foram capazes de produzir fitormônios tipo AIA.
\end{abstract}

Termos de indexação: fixação biológica de nitrogênio, pastagens, bactérias diazotróficas, ácido indol acético.

\footnotetext{
(1) Parte da Tese de Doutorado do primeiro autor, apresentada no Curso de Pós-Graduação em Ciência do Solo, Universidade Federal Rural do Rio de J aneiro - UFRRJ. Recebido para publicação em setembro de 2002 e aprovado em outubro de 2003.

(2) Pesquisador da Embrapa Cerrados. CEP 73301-970 Planaltina (DF), E-mail: fabio@cpac.embrapa.br

(3) Pesquisador da Embrapa Agrobiologia. CEP 23851-970 Seropédica (RJ ) E-mail: sac@cnpab.embrapa.br
} 

SUMMARY: IDENTIFICATION OF Azospirillum amazonense ISOLATES ASSOCIATED TO Brachiaria spp. AT DIFFERENT STAGES AND GROWTH CONDITIONS, AND BACTERIAL PLANT HORMONE PRODUCTION

\begin{abstract}
Thereis evidencethat pastures formed by somespecies of thegenus Brachiaria could be benefited by thebiol ogical nitrogen fixation process (BNF), which would givethesepastures a higher longevity. Among the diazotrophic bacteria found in association with these forage grasses, thespecies Azospi rillum amazonenseis most outstanding. This study aimed to verify theinfluence of theBrachiaria species, pasturemanagement, and seasonal variations on the A. amazonense populations associated to theplant roots. Different pastures (B. humidicola, B. decumbens, and B. brizantha) wereimplanted in Cerrado and Atlantic F orest ecosystem areas. Two management systems with different stocking rates wereevaluated and samples coll lected at different times of theyear. TheA. amazonense populations werequantified, and the isolates' identity as well as the capacity to produce phyto-hormones like IAA in growth media tested. A. amazonenseisolates wereobtained from root samples of thethreevaluated Brachiaria species. The estimates of bacterial populations varied from $10^{3}-10^{7} \mathrm{cells}$. $\mathrm{g}^{-1}$ of roots. In theCerrado, thesampling timehad a si gnificant influenceon thepopulation of these bacteria. Data from theAtlantic forest showed that Brachiaria plants from different species and pastures under different stocking rates can present distinct population numbers of A. amazonense associated to their roots. The "analise de restrição do DNA ribossome amplificado" amplifed ribossomal DNA restriction analysis (ARDRA) techniqueconfirmed theidentity of all tested isolates. Theseisol ates wer eabl eto producephyto-hormones likel AA.

Index terms: biological nitrogen fixation, pasture degradation, diazotrophic bacteria, indol aceticacid.
\end{abstract}

\section{INTRODUÇÃO}

Dentre os fatores que levam à degradação das pastagens, a limitação de $\mathrm{N}$ é considerada um dos mais importantes (Oliveira et al., 1997). Este nutriente pode ser removido do sistema solo-planta mediante a exportação por produto animal (carne, principalmente), lixiviação, denitrificação e volatilização dos depósitos na forma de excretas bovinas (Ferreira et al., 1995; 2000).

Mesmo com observações de perdas de nitrogênio nessas pastagens, relatos na literatura indicam que determinados genótipos de Brachiaria não apresentam reduções significativas em sua produtividade. As perdas de N poderiam estar sendo compensadas pela fixação biológica do nitrogênio atmosférico ( $\mathrm{FBN})$, que seria responsável pela introdução de 30 a $40 \mathrm{~kg} \mathrm{ha}^{-1} \mathrm{ano}^{-1}$ de N no sistema solo-planta (Boddey \& Victoria, 1986; Loureiro \& Boddey, 1988). Em sistemas de manejo extensivo, nos quais as vias de perdas são menos expressivas, a quantidade de nitrogênio fixado pode ser suficiente para proporcionar um balanço nulo ou até positivo de N para o sistema solo-planta e, com isso, permitir maior longevidade da pastagem com uma produtividade aceitável.

Estudos de isolamento e identificação de bactérias fixadoras de $\mathrm{N}_{2}$ em gramíneas forragei ras ocorreram, em sua maioria, entre as décadas de 60 e 80, com destaque para algumas espécies do gênero Azospirillum (Neyra \& Döbereiner, 1977). Bactérias pertencentes a este gênero têm sido encontradas em associação com grande número de espécies de cereais e gramíneas forragei ras, cultivadas tanto em clima tropical como em clima temperado. No entanto, nem todas as espécies têm sido encontradas colonizando plantas em diferentes localidades. A. amazonense, por exemplo, só foi isolado até hoje no Brasil, exceto por sua detecção em amostras de plantas de cana-de-açúcar cultivadas no Havaí, Tailândia e Argentina (Döbereiner, 1992; Monzón de Asconegui \& Sirolli, 1985), sendo este o motivo de ser tão pouco estudado, quando comparado com A. lipoferum ou A. brasilense. A. amazonense apresenta alta incidência e altos números em associação com gramíneas forrageiras, dentre elas a Brachiaria (Souto, 1982; Bal dani, 1984; Magalhães \& Döbereiner, 1984), e adaptabilidade a pH ácido (Magalhães et al., 1983), característica comum à maioria dos solos brasileiros.

Embora alguns estudos pioneiros tenham demonstrado a presença de bactérias diazotróficas em Brachiaria spp., nenhum deles foi feito de forma regular e sequer por um intervalo de tempo de um ano com as plantas submetidas a pastejo. Não existe até o momento nenhum registro de avaliação das populações destes organismos inerente às áreas de 
pastagens ou em relação aos genótipos de Brachiaria. Como a dinâmica de microrganismos do solo e daqueles encontrados no interior das plantas está condicionada à própria vegetação, é possível que diferentes genótipos de Brachiaria possam exercer um efeito sel etivo sobre as populações destes, o que poderia resultar em diferentes respostas quanto à contribuição da FBN obtida por cada um destes genótipos.

Apesar de a fixação biológica de nitrogênio por Azospirillum ter sido foco de bastante atenção da comunidade científica por muitos anos, existem evidências crescentes de que parte da contribuição de bactérias deste gênero para as plantas deve-se à produção de hormônios. Bashan \& Holguin (1997) relatam queé óbvio quefitormônios, principalmente o ácido indol-acético (AIA), excretados por Azospirillum, desempenhem papel essencial na promoção do crescimento de plantas em geral.

Neste trabalho, objetivou-se estabelecer a influência da espécie de Brachiaria, manejo da pastagem esazonalidadesobre a presença e número de bactérias da espécie Azospirillum amazonense associadas às raízes destas plantas, assim como confirmar a caracterização dos isol ados e averiguar sua capacidade em produzir hormônios de crescimento de plantas do tipo ácido indol acético.

\section{MATERIAL E MÉTODOS}

\section{Localização e instalação dos experimentos}

Diferentes pastagens foram estabelecidas em regiões do ecossistema Cerrado sob Latossolo Vermelho-E scuro (Santo Antônio de Goiás, GO) e de Mata Atlântica sob Argissol o Amarel o (I tabela, BA). Os tratamentos, introduzidos no ano de 1998, foram compostos de piquetes de Bachiaria humidicola, B. decumbens cv. Basilisk eB. brizantha cv. Marandu, nos quais foram feitas a calagem, com aplicação de 1,5 t ha-1 de calcário dolomítico, e a adubação utilizando-se $50 \mathrm{~kg} \mathrm{ha}^{-1}$ de $\mathrm{P}_{2} \mathrm{O}_{5}$ na forma de superfosfato simples no plantio. Estes piquetes foram divididos e distribuídos para manter duas taxas de lotação. Na primeira, menor taxa de lotação, a área era pastejada atéas plantas chegarem a uma altura de $30 \mathrm{~cm}$. Na segunda, maior taxa de lotação, a área era pastejada atéas plantas chegarem a uma al tura de $15 \mathrm{~cm}$. Estas áreas foram pastejadas com gado anelorado em sistema de pastejo contínuo, cada piquete continha animais fixos, denominados "testers", e, conforme a lotação desejada, havia a inclusão de mais animais denominados "volantes" queficavam em pasto reserva quando não utilizados. No experimento de Itabela, além dos diferentes sistemas de manejo, também foram avaliadas pastagens com diferentes idades, implantadas nos anos de 1990 (B. decumbens), 1988 (B. humidicola) e 1993 (B. brizantha). Nestas áreas, foram aplicados $50 \mathrm{~kg} \mathrm{ha}^{-1} \mathrm{de}_{2} \mathrm{O}_{5}$ na forma de superfosfato simples em cobertura. No quadro 1, são apresentados os resultados das análises químicas e classe textural dos solos das áreas experimentais.

\section{I solamento, caracteri zação e quantificação de Azospirillum amazonense}

As amostras (três repetições) de raízes de cada um dos tratamentos foram coletadas al eatoriamente dentro de cada piquete. Estas coletas foram realizadas em diversas épocas do ano, abrangendo diferentes estações climáticas. As amostras col etadas foram cuidadosamente lavadas em água corrente, para que fossem utilizadas as técnicas tradicionais descritas por Döbereiner et al. (1995). Dez gramas de raízes lavadas foram triturados em $90 \mathrm{~mL}$ de solução salina ( $\mathrm{NaCl}$ 0,85\%) e diluídos serialmente até $10^{-7}$. De cada diluição foi retirado $0,1 \mathrm{~mL}$ e inoculado em frascos com $5 \mathrm{~mL}$ de meio de cultura LGI semi-sólido e sem nitrogênio, semisel etivo para Azospirillum amazonense. Considerouse, como crescimento positivo, a formação de uma película típica na superfície do meio após sete dias de incubação a $30^{\circ} \mathrm{C}$.

Os frascos com crescimento positivo na mais alta diluição foram utilizados na repicagem para novo meio semi-sólido. Após incubação, retiraram-sealíquotas

Quadro 1. Características químicas e classe textural do Latossolo Vermelho-E scuro do sítio experimental de Goiás e do Argissolo Amarelo do sítio experimental da Bahia, na profundidade de $0-20 \mathrm{~cm}$

\begin{tabular}{|c|c|c|c|c|c|c|c|}
\hline Sítio experimental & pH $\left(\mathrm{H}_{2} \mathrm{O}\right)$ & $\mathrm{Al}^{3+}$ & $\mathrm{Ca}^{2+}$ & $\mathbf{M g}^{2+}$ & $\mathbf{K}$ & $\mathbf{P}$ & Textura \\
\hline & & \multicolumn{3}{|c|}{$\mathrm{cmol}_{\mathrm{c}} \mathrm{dm}^{-3}$} & \multicolumn{2}{|c|}{$-\mathrm{mg} \mathrm{kg}^{-1}$} & \\
\hline $\begin{array}{l}\text { Goiás } \\
\text { Bahia }\end{array}$ & 5,3 & 0,1 & 3,0 & 1,7 & 104,0 & 2,0 & Franco-argilosa \\
\hline Pastagens com mais de 9 anos & 5,8 & 0,2 & 2,6 & 1,5 & 78,0 & 2,0 & Areia Franca \\
\hline Pastagens estabel eci das em 1998 & 5,5 & 0,2 & 2,2 & 0,9 & 98,0 & 4,0 & Franco-arenosa \\
\hline
\end{tabular}

$\mathrm{Ca}, \mathrm{Mg}$ e Al extraídos em $\mathrm{KCl} 1 \mathrm{~mol} \mathrm{~L}^{-1}$; $\mathrm{K}$, e P extraídos em solução de Mehlich-1. 
para observação da morfol ogia celular ao microscópio de contraste de fase. Outra alíquota foi utilizada para riscagem em placas que continham meio LGI sólido. A observação da morfologia das células sob microscopia ótica de contraste de fasee a morfol ogia das colônias no meio semi-específico (LGI) foram utilizadas para caracterizar as bactérias isoladas como sendo A. amazonense.

Com o material obtido pela diluição seriada das amostras em solução salina $\left(10^{-1}\right.$ até $\left.10^{-7}\right)$, a população de bactérias foi estimada pelo método do número mais provável (NMP), consultando a tabela de McCrady para três repetições por diluição.

\section{Análise estatística}

Os resultados referentes às contagens do número de células pelo método do NMP foram analisados segundo o fatorial 3 (espécies) $\times 2$ (sistemas de manejo), com o fator coletas como um "Split Plot". Os resultados for am analisados com a utilização do software MSTAT-C, versão 2.10 (MSTAT Director, Michigan State U niversity).

\section{Confirmação da caracterização dos isolados de A. amazonense por meio da análise de restrição do DNA ribossomal amplificado (ARDRA)}

- Extração do DNA - Método de extração alcalina adaptado de Audy et al. (1996).

As bactérias foram cultivadas por $48 \mathrm{~h}$ em meio líquido DY GS (Rodrigues Neto et al ., 1986) e 1,0 mL dessa suspensão foi centrifugado a 10.000 rpm por $2 \mathrm{~min}$. O sobrenadantefoi descartado e o precipitado ressuspendido em 1,0 mL deágua Milli-Q estéril (esse procedimento foi repetido por três vezes). Após a última lavagem, repetiu-se a centrifugação e, desta vez, o precipitado foi ressuspendido em $0,5 \mathrm{~mL}$ de $\mathrm{NaOH}\left(0,5 \mathrm{~mol} \mathrm{~L}^{-1}\right)$, ficando em repouso por $10 \mathrm{~min}$ à temperatura ambiente para a completa lise das células. Em seguida, $10 \mu \mathrm{L}$ do material lisado foram col etados e diluídos em $490 \mu \mathrm{L}$ de solução de Tris$\mathrm{HCl} 20 \mathrm{mM}, \mathrm{pH}$ 8,0. Este material foi estocado a $20^{\circ} \mathrm{C}$ até ser utilizado nas reações de PCR.

- PCR (Reação em cadeia da polimerase) Amplificação da região 16S DNAr

A reação de amplificação ocorreu em $50 \mu \mathrm{L}$ de uma mistura reacional de 1,25 $\mu \mathrm{L}$ detween $20 ; 5,0 \mu \mathrm{L}$ deTampão (10 X); 4,0 $\mu \mathrm{L}$ de $\mathrm{MgCl}_{2}(25 \mathrm{mM}) ; 1,0 \mu \mathrm{L}$ de $\operatorname{dNTP}(2,5 \mathrm{mM}) ; 1,25 \mu \mathrm{L}(5,0 \mathrm{pmol})$ dos Primers Y1 e Y3 (Young et al., 1991); 0,40 $\mu$ L de Taq DNA Polimerase (5 $\mathrm{UL}^{-1}$ ) (Promega, Madison, EUA) e 10,0 $\mu \mathrm{L}$ de amostra de DNA molde. As condições de termociclagem foram: 1 ciclo inicial de desnaturação (93 ${ }^{\circ} \mathrm{C}$ por $2 \mathrm{~min}$ ), seguido por 35 didos intermediários (93 ${ }^{\circ} \mathrm{C}$ por 45 seg; $62^{\circ} \mathrm{C}$ por 45 seg; $72{ }^{\circ} \mathrm{C}$ por $2 \mathrm{~min}$ ), e 1 ciclo terminal de extensão ( $72{ }^{\circ} \mathrm{C}$ por $5 \mathrm{~min}$ ), seguido por resfriamento $\left(15^{\circ} \mathrm{C}\right.$ por $\left.15 \mathrm{~min}\right)$, para parar a reação.
Os fragmentos amplificados foram observados com o uso de el etroforese em gel de agarose 1,2 \% em TAE, $65 \mathrm{~V}$, por 2,5 h. As bandas resolvidas no gel foram visualizadas após col oração com brometo de etídeo sob iluminação ultraviol eta e fotografadas com filme Polaroid tipo 667.

\section{- Restrição dos fragmentos ampl ificados}

Os produtos de amplificação das reações de PCR foram incubados a $37^{\circ} \mathrm{C}$ em banho-maria por $3 \mathrm{~h}$ com as endonucleases de restrição HaellI , Alu I , Rsa I e Cfol (GibcoBRL, Gaithersburg, EUA). Para um volume final de $15 \mu \mathrm{L}$ de reação, cada sistema de restrição conteve $5 U$ da enzima de interesse, 2,0 $\mu \mathrm{L}$ de tampão de reação $10 \times$ e $8 \mu \mathrm{L}$ de material ampl ificado. Os produtos da reação foram anal isados em gel deagarose por el etrofor ese (3,0 \% em tampão TAE, 50 V, 4 h), visualizados após coloração com brometo de etídeo sob iluminação ultravioleta e fotografados com filme Polaroid tipo 667.

\section{- Análises deagrupamento}

Os padrões de migração gerados foram comparados e suas semel hanças estimadas pelo coeficiente de J accard (Rohlf, 2000). Os isolados foram agrupados pelo método das médias das distâncias (Bussabe et al., 1990) e representados graficamente por um dendrograma (NTSYS-pc, versão 2.1, Exeter Software, USA).

\section{Produçãodehormôniodecrescimento (AIA-ácido indol acético) por isolados de A. amazonense}

A capacidade de produção de AI A por isolados de A. amazonenseescol hidas para este teste ao acaso e comparados com estirpes referência, foi analisada pela utilização do método descrito por Sarwar \& Kremer (1995), com al gumas modificações. Culturas de células crescidas por $24 \mathrm{~h}$ a $30^{\circ} \mathrm{C}$ em meio LGI líquido com $0,1 \%$ de $\mathrm{KNO}_{3}$ tiveram sua densidade ótica ajustada para 0,5 a $500 \mathrm{~nm}$. Foram adicionados $2 \mathrm{~mL}$ desta suspensãoa $28 \mathrm{~mL}$ de meio L GI acrescido de $100 \mu \mathrm{g} \mathrm{mL}^{-1}$ deL-triptofano. Foram utilizadas três repetições para cada isolado. Os erlenmeyers foram incubados no escuro por $72 \mathrm{~h}$ a $30^{\circ} \mathrm{C}$. A pós esteperíodo, as culturas foram ajustadas para $10^{8}$ células $\mathrm{mL}^{-1}$. Posteriormente, estas culturas foram filtradas com a utilização de filtros com malha de 0,2 $\mu \mathrm{m}$. U ma alíquota de $150 \mu \mathrm{L}$ do material filtrado foi aplicada em microplacas de poliestireno (capacidade para $300 \mu \mathrm{L}$ ), devendo reagir com $100 \mu \mathrm{L}$ do reagente de Salkowisk ( $1 \mathrm{~mL}$ de $\mathrm{FeCl}_{3} \cdot 6 \mathrm{H}_{2} \mathrm{O}$ 0,5 M em $50 \mathrm{~mL}$ de $\mathrm{HClO}_{4} 35 \%$ ). Após incubaçãoà temperatura ambiente por $30 \mathrm{~min}$, observou-se a formação de uma cor rósea, e as leituras de absorbância foram realizadas utilizando um espectrofotômetro Labsystem Multskan Plus (Labsystems Oy, Helsinki, Finlândia) dotado de filtro de interferência de $492 \mathrm{~nm}$. A concentração de AIA pôde ser estimada com uma curva-padrão preparada, utilizando-se $0 ; 25 ; 50 ; 100$; 150; 200; $200 \mu \mathrm{M}$ deAIA puro. 


\section{RESULTADOS E DISCUSSÃO}

\section{Quantificação de Azospi rillum amazonense}

Tantonas amostras provenientes deGoiás, quanto naquelas oriundas da Bahia, a quantidade de bactérias estimada pelo método do número mais provável variou de $10^{3}-10^{7}$ células $\mathrm{g}^{-1}$ de raízes (Quadros 4, 5 e 6).

Os resultados relacionados com o sítio experimental deGoiás não apresentaram diferenças significativas entre os números de células de A. amazonense encontrados em associação com as diferentes espécies de Brachiaria, ao contrário do que ocorreu com os resultados relacionados com o sítio experimental da Bahia, mostrando que plantas de Brachiaria de diferentes espécies podem

Quadro 2. Isolados de Azospirillum amazonense utilizados nos trabalhos de ARDRA e, ou, produção de AIA

\begin{tabular}{ccc}
\hline \multicolumn{3}{c}{ Espécie de Brachiaria } \\
\hline B. decumbens & B. humidicola & B. brizantha \\
\hline $37 \mathrm{Ce}^{(1)}$ & $64 \mathrm{Ce}$ & $27 \mathrm{Ce}$ \\
$38 \mathrm{Ce}$ & $77 \mathrm{Ma}$ & $36 \mathrm{Ce}$ \\
$53 \mathrm{Ce}$ & $79 \mathrm{Ma}$ & $48 \mathrm{Ce}$ \\
$72 \mathrm{Ma}(2)$ & $80 \mathrm{Ma}$ & $85 \mathrm{Ma}$ \\
$73 \mathrm{Ma}$ & $81 \mathrm{Ma}$ & $104 \mathrm{Ce}$ \\
$76 \mathrm{Ma}$ & $83 \mathrm{Ma}$ & $124 \mathrm{Ce}$ \\
$87 \mathrm{Ma}$ & $84 \mathrm{Ma}$ & $125 \mathrm{Ce}$ \\
$118 \mathrm{Ce}$ & $86 \mathrm{Ma}$ & $131 \mathrm{Ce}$ \\
$120 \mathrm{Ma}$ & $107 \mathrm{Ce}$ & $138 \mathrm{Ce}$ \\
$134 \mathrm{Ce}$ & $119 \mathrm{Ma}$ & $139 \mathrm{Ma}$ \\
$137 \mathrm{Ce}$ & $123 \mathrm{Ce}$ & \\
$140 \mathrm{Ma}$ & $127 \mathrm{Ce}$ & \\
& $132 \mathrm{Ce}$ & \\
& $135 \mathrm{Ce}$ & \\
\hline
\end{tabular}

${ }^{(1)}$ Cerrados. $^{(2)}$ Mata Atlântica. apresentar números populacionais diferentes de A. amazonenseassociados à suas raízes. Nestesítio, mai ores números de células foram encontrados nas raízes da espécie $B$. humidicola, seguida por B. decumbense B. brizantha (Quadro 4).

Estas diferenças poderiam explicar, em parte, trabal hos comoo deAlvimet al. (1990), que, comparando a produção forrageira de algumas espécies de Brachiaria, mostraram que, sem adubação nitrogenada, B. brizantha apresentou os menores valores de produtividadeanual em massa da matéria seca, enquanto B. decumbens mostrou a maior produtividade dentre as espécies testadas. Porém, $B$. brizantha foi a espécie que mais respondeu a aplicações deN. Boddey \& Victoria (1986) concluíram em seu trabal ho que $B$. humidicola e $B$. decumbens receberam maiores contribuições da FBN associada a suas raízes, quando comparadas às espécies $B$. ruziziensise $B$. radicans. E moutro estudo, Loureiro \& Boddey (1988), utilizando a técnica de diluição isotópica de ${ }^{15} \mathrm{~N}$, destacaram uma possível taxa deFBN superior em B. humidicola, quando comparada com B. decumbens, B. ruziziensis e B. radicans.

Um exemplo de que diferenças nas populações de determinada espécie de bactéria diazotrófica podem ter influência sobre variações nas taxas de FBN está descrito no trabalho de Döbereiner (1977), que, estudando genótipos de Paspalum notatum ea ocorrência de Azotobacter paspali, correlaciona as diferenças na atividade da nitrogenase com a população desses microrganismos.

Os resultados apresentados no quadro 5 apontam para um efeito da taxa de lotação animal sobre a população de $A$. amazonense, associada às raízes de Brachiaria oriundas dos experimentos da Bahia. As raízes das pastagens sob taxa delotaçãoanimal mais alta parecem estar associadas a maiores populações destas bactérias. Mesmo com uma pequena diferença entre os números populacionais, estas foram significativas estatisticamente para bactérias associadas a pastagens com mais de nove anos.

Quadro 3. Origem das estirpes utilizadas nos trabalhos de ARDRA e, ou, produção de AIA

\begin{tabular}{lllll}
\hline Espécie/estirpe & Fonte(1) & Planta & Amostra & Referência \\
\hline $\begin{array}{l}\text { A. lipoferum } \\
\text { Sp59 }\end{array}$ & BR11008 & Trigo & Raízes & Tarrand et al. (1978) \\
$\begin{array}{l}\text { A. brasilense } \\
\text { Sp7 }\end{array}$ & & & Tarrand et al. (1978) \\
Cd & BR11002 & Digitaria decumbens & Rizosfera & Tarrand et al. (1978) \\
$\begin{array}{l}\text { A. amazonense } \\
\text { CBAMC }\end{array}$ & BR11001 & Cynodon dactylon & Rizosfera & -- \\
$\begin{array}{l}\text { Y2 } \\
\text { H. seropedicae }\end{array}$ & BR11145 & Cana-de-açúcar & Raízes & Magalhães et al. (1983) \\
Z67 & B Hyparrenia rufa & Raízes & Baldani et al. (1996) \\
\hline
\end{tabular}

(1) BR - Coleção de Culturas da Embrapa Agrobiologia. 
A herbivoria exerce papel importante na exsudação de compostos de C pelas raízes (Holland et al., 1996). Ruess \& McNaughton (1987) mostraram, em um estudo com pastagens do Serengueti (África Central), que a biomassa microbiana do solo aumentou com o aumento da intensidade de pastejo, até decrescer com intensidades de pastejo mais altas. Este decréscimo pode estar relacionado com a redução de al ocação de carbono para as raízes nestas condições. Em oposição a este relato, Davidson \& Milthorpe (1966) mediram a troca de C entre raízes e parte aérea de Dactylis glomerata e concluíram que as raízes continuavam a ser um dreno de $C$, independentemente da severidade da desfoliação.

Kraffczyk et al. (1984) notaram uma baixa relação $\mathrm{N}: \mathrm{C}$ nos compostos exsudados pelas plantas. Esperase que o crescimento neste tipo de fonte seja favorável aos organismos que conseguem utilizar o nitrogênio atmosférico. Estes mesmos autores também relataram o aumento da atividade da nitrogenase por adição de produtos do metabol ismo radicular (Kraffcyk et al., 1984).

Parece que o desafio seria encontrar uma taxa de lotação animal que influenciasse positivamente as bactérias diazotróficas associadas a estas plantas e que não possibilitasse um decréscimo muito acentuado na deposição da serapilheira e, conseqüentemente, na reciclagem de $\mathrm{N}$ do sistema, e que as perdas de $\mathrm{N}$ fossem pelo menos contrabalançadas com os possíveis ganhos de nitrogênio de forma a manter estável o nível de $\mathrm{N}$ e de matéria orgânica do solo.

O quadro 6 mostra que, em Goiás, a época de coleta apresentou efeitos significativos sobre a população de bactérias associadas às raízes das plantas de Brachiaria. Vários autores têm afirmado que estes efeitos podem ser explicados por fatores ambientais, neste caso, principalmente pelas taxas de precipitação pluvial. O clima desta área é caracterizado como Aw (tropical com estação seca no inverno), segundo Koeppen.

A influência defatores ambientais, principalmente estresse hídrico sobre as populações de mi crorganismos diazotróficos e sobre o processo de fixação biológica de nitrogênio, foi demonstrada em diversos trabalhos. Costa \& Ruschel (1981), trabal hando com plantas de cana-de-açúcar, verificaram que a distribuição demicrorganismos fixadores de $\mathrm{N}_{2}$ sofria influência de acordo com a época do ano, mostrando que a atividade de microrganismos no interior do

Quadro 4. Número de células de Azospirill um amazonense associadas a três espécies de Brachiaria em experimentos na Fazenda Agropecuária Lopes (GO) e I tabela (BA)

\begin{tabular}{llc}
\hline \multirow{2}{*}{ Espécie de Brachiaria } & Bahia $(\mathbf{n}=18)$ \\
\cline { 2 - 3 } & Pastagem implantada em $1998 \quad$ Pastagem com mais de 9 anos $(n=30)$ \\
\hline
\end{tabular}

Número(1) de células (x 104) $\mathrm{g}^{-1}$ de raízes frescas
B. brizantha
B. decumbens
$6,92 \mathrm{~b}$
$67,60 \mathrm{a}$
$8,13 \mathrm{~b}$
6,02 a
B. humidicola
263,03 a
$8,91 \mathrm{~b}$
4,17 a
C.V. (\%)
14,16
18,17
5,25 a
17,04

(1) As análises estatísticas foram feitas com os dados transformados em log. Médias seguidas de mesma letra, em cada coluna, não diferem entre si pelo teste Tukey a $5 \%$.

Quadro 5. Número de células de Azospi rill um amazonense associadas a Brachiaria sob baixa e alta taxas de lotação em experimentos na Fazenda Agropecuária Lopes (GO) e Itabela (BA)

\begin{tabular}{|c|c|c|c|}
\hline \multirow{2}{*}{ Taxa de lotação } & \multicolumn{2}{|c|}{ Bahia $(n=27)$} & \multirow{2}{*}{ Goiás ( $n=45)$} \\
\hline & Pastagem implantada em 1998 & Pastagem com mais de 9 anos & \\
\hline \multicolumn{4}{|c|}{ Número(1) de células $\left(x 1^{1} 0^{4} \mathrm{~g}^{-1}\right.$ de raízes frescas } \\
\hline $\begin{array}{l}\text { Baixa } \\
\text { Alta }\end{array}$ & $\begin{array}{l}38,90 \text { a } \\
63,10 \text { a }\end{array}$ & $\begin{array}{r}8,51 \mathrm{~b} \\
32,36 \mathrm{a}\end{array}$ & $\begin{array}{l}6,02 \mathrm{a} \\
4,17 \mathrm{a}\end{array}$ \\
\hline C.V. (\%) & 14,16 & 18,17 & 17,04 \\
\hline
\end{tabular}


colmo foi bastante irregular na primavera, relativamente uniformeno verão ecaiu bruscamente no outono. Bellone et al . (1996) mostraram que, em solos com progressiva deficiência hídrica (mais de 20 dias), as plantas decana-de-açúcar apresentaram baixos níveis de atividade de redução de acetileno (ARA) associados a um baixo número de microrganismos por grama de raiz. Reis J r. et al. (2000) também encontraram variações no número de bactérias diazotróficas associadas à cana-deaçúcar em virtude das diferenças nas taxas de preci pitação pluvial.

Provavelmente, uma melhor distribuição de chuvas na região de Mata Atlântica, cujo clima é caracterizado como Af, segundo Koeppen (tropical sem estação seca), fez com que, nos experimentos da Bahia, não fossem observados efeitos da época de coleta sobrea população de Azospirillum amazonense (Quadro 7).

Confirmação da caracterização dos isolados de A. amazonense por meio de ARDRA

- PCR

Amplificou-se por PCR a região 16S do DNAr de isolados de raízes provenientes das três espécies de

Quadro 6. Número de células de Azospirillum amazonense associadas a Brachiaria em diferentes coletas nos experimentos da Fazenda Agropecuária Lopes (GO)

\begin{tabular}{lc}
\hline \multicolumn{1}{c}{ Coleta $(\mathbf{n}=\mathbf{1 8})$} & $\begin{array}{c}\text { Número de célula } \\
\left(\mathbf{x} \mathbf{1 0}^{\mathbf{4}}\right) \mathbf{~ g}^{-1} \text { raízes frescas }\end{array}$ \\
\hline Coleta 1 (agosto de 1998) & $3,71 \mathrm{~b}$ \\
Coleta 2 (fevereiro de 1999) & $6,02 \mathrm{~b}$ \\
Coleta 3 (agosto de 1999) & $0,47 \mathrm{C}$ \\
Coleta 4 (dezembro de 1999) & $64,56 \mathrm{a}$ \\
Coleta 5 (março de 2000) & $4,17 \mathrm{~b}$ \\
C.V. (\%) & 17,04 \\
\hline
\end{tabular}

As análises estatísticas foram feitas com os dados transformados em log. Médias seguidas de mesma letra, em cada coluna, não diferem entre si pelo teste Tukey a $5 \%$.
Bracharia coletadas nos dois sítios experimentais, assi $m$ como das estirpes de referência de Azospirillum amazonense (CBAMC, Y2), A. brasilense (Cd, Sp7), A. lipoferum (Sp59) e Herbaspirillum seropedicae (Z67). Todos os produtos de amplificação apresentaram uma única banda com tamanho de aproximadamente $1450 \mathrm{pb}$ (Figura 1). Estetamanho do fragmento corresponde ao esperado, pois os primers utilizados flanqueiam quase todo ogene, que apresenta um tamanho médio de 1.500 pb (Young et al., 1991).

- ARDRA e análises deagrupamento

O dendrograma construído a partir do perfil de fragmentos de restrição da região 16S DNAr agrupou os 33 isolados de raízes de Bracharia précaracterizados morfologicamente como A. amazonense(Figura 2). Foram formados dois grupos muito similares ( $\cong 95 \%$ de similaridade) nos quais foram colocadas as duas estirpes de referência de A. amazonense (CBAM C, Y2). As outras estirpes de

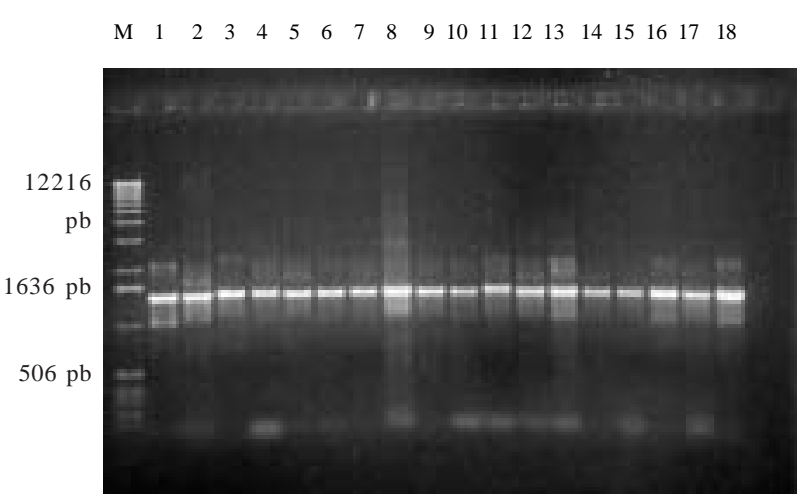

Figura 1. Produtos de amplificação da região 165 DNAr de estirpes de referência de diferentes diazotróficos e novos isolados de Azospi rill um amazonense provenientes de três espécies de Brachiaria. M (marcador 1Kb Ladder), 1 (Y2), 2 (CBAMC), 3 (Z67), 4 (Sp7), 5 (Sp59), 6 (53), 7 (137), 8 (120), 9 (84), 10 (125), 11 (138), 12 (85), 13 (76), 14 (119), 15 (134), 16 (139), 17 (72), 18 (136).

Quadro 7. Número de células de Azospi ri ll um amazonenseassociadas a Brachiaria em diferentes coletas nos experimentos em I tabela (BA)

\begin{tabular}{ccc}
\hline Coleta $(\mathbf{n}=\mathbf{1 8})$ & Pastagem implantada em 1998 & Pastagem com mais de 9 anos \\
\hline & Número(1) de células $\left(\times 10^{4}\right) \mathrm{g}^{-1}$ de raízes frescas \\
Coleta 1 (maio de 1999) & $91,20 \mathrm{a}$ & $21,38 \mathrm{a}$ \\
Coleta 2 (novembro de 1999) & $41,69 \mathrm{a}$ & $9,77 \mathrm{a}$ \\
Coleta 3 (agosto de 2000) & $32,36 \mathrm{a}$ & $22,39 \mathrm{a}$ \\
C.V. (\%) & 14,16 & 18,17 \\
(1) As análises estatísticas foram feitas com os dados transformados em log. Médias seguidas de mesma letra, em cada coluna, não \\
diferem entre si pelo teste Tukey a 5\%.
\end{tabular}




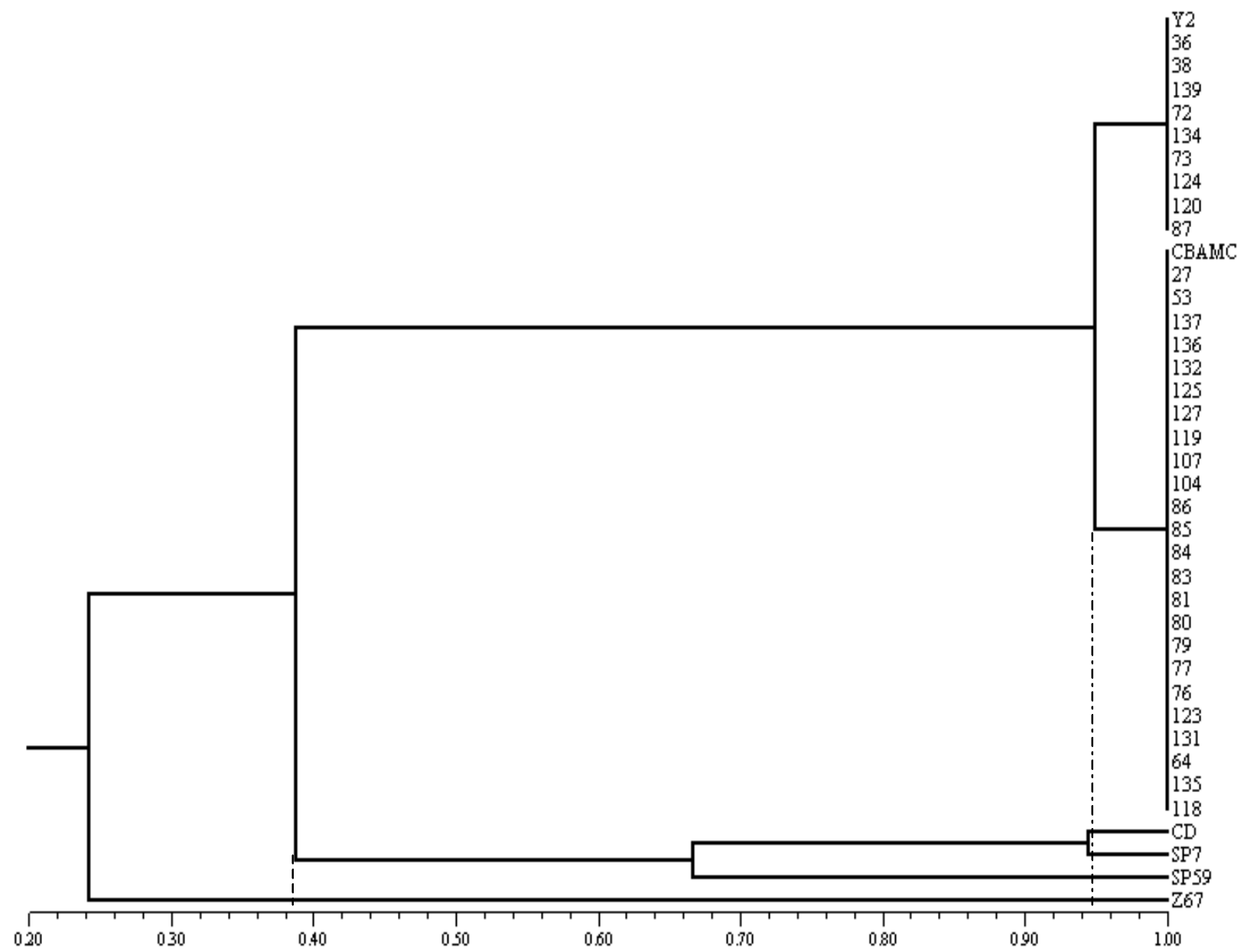

Figura 2. Dendrograma de similaridade de 33 isolados de raízes provenientes das três espécies de Bracharia estudadas e das estirpes de Azospi rill um amazonense (CBAMC, Y2), A. brasilense (Cd, Sp7), A. li poferum (Sp59) e Herbaspi rill um seropedi cae (Z67).

referência formaram grupos distintos, para A. brasilense (Cd, Sp7), A. lipoferum (Sp59) e Herbaspi rillum seropedicae(Z67), todos afastados pelo menos $60 \%$ de $A$. amazonense. A análise deste dendrograma vai ao encontro das afirmações de Dekhil et al. (1997), que, após o seqüenciamento da 16S RNAr de espécies do gênero Azospirillum, mostraram a formação de dois subgrupos distintos, com A. lipoferum e A. brasilense fazendo parte do primeiro, e A. amazonense, mais afastado, do segundo subgrupo.

\section{Produçãodehormôniodecrescimento(AIA-ácido indol acético) por isolados de A. amazonense}

Todos os isolados testados foram capazes de produzir AIA (Figura 3). A quantidade de AIA produzida variou de 35 a $110 \mu \mathrm{M}$. Estes valores são similares aos observados por Mascarua-Esparza et al. (1988), que variaram de 28,54 a 97,03 $\mu \mathrm{M}$ em isolados de $\mathrm{A}$. lipoferum originários de plantas cactáceas no México. Crozier et al. (1988), também trabal hando com isolados deA. lipoferum, oriundos de raízes de milho, obtiveram uma produção variando de 0,0 a 85,9 $\mu \mathrm{M}$ de AIA. Quando estes mesmos autores estudaram a produção de AIA por isolados de A. brasilense, os valores apresentados foram maiores, variando de 7,99 a 148,97 $\mu \mathrm{M}$ (Crozier et al., 1988) e 205 a $428 \mu \mathrm{M}$ (Mascarua-E sparza et al., 1988). Radwan (1999) também mostrou grande variabilidade entre espécies de Azospirillum quanto à produção de AIA, com valores variando de 19,2$432 \mu \mathrm{M}$.

As diferenças encontradas nestetrabal ho quanto às populações de Azospirillum amazonense associadas a diferentes genótipos de Brachiaria podem ser indicadas como possíveis fatores de influência nas taxas de FBN associadas a estas plantas, assim como na sua adaptabilidade a solos de baixa fertilidade. Um manejo adequado, associado à escol ha de plantas (genótipos), que, além de serem adaptadas a condições edafoclimáticas vigentes, sejam também eficientes na captação do $\mathrm{N}_{2}$ atmosférico, seria um importante passo para se alcançar sustentabilidade nos sistemas de pastagem. 


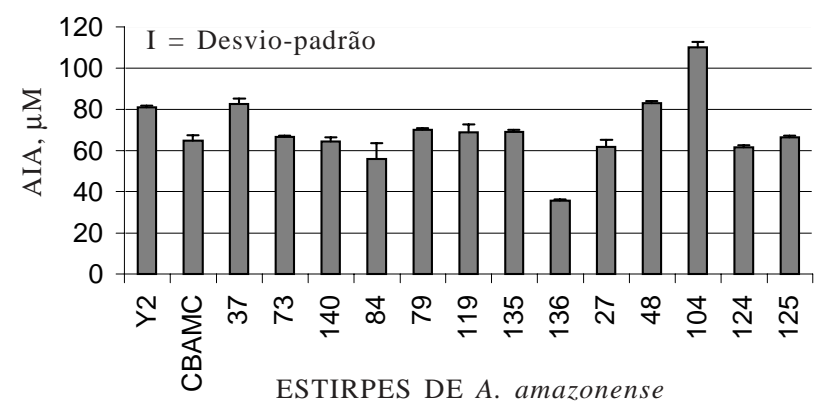

Figura 3. Produção de AI A por estirpes de referência de Azospirillum amazonense e por isolados de raízes de Brachiaria spp.

A associação entre Azospirillum e Brachiaria também pode vislumbrar a possibilidade de inoculação de pastagens. Itzigsohn et al. (2000) mostraram que a inoculação de Azospirillum em pastagens tem grande potencial para tornar-seuma técnica aplicável a estes sistemas em condições de déficit hídrico e/ou baixa fertilidade. Apesar de existirem, em outros países, formulações de inoculantes de Azospirillum comercialmente disponíveis, estudos sobre sua utilização, assim como de outras rizobactérias promotoras do crescimento de plantas em pastagens, são muito escassos. No entanto, o uso destes microrganismos associado a um adequado manejo do solo, baseado em comparações com a apl icação de fertilizantes, parece ser mais vantajoso economicamente (Ok on \& Vanderleyden, 1997) e não apresenta, do ponto de vista ecológico e ambiental, impacto negativo ao meio ambiente (Itzigsohn et al., 2000).

\section{CONCLUSÕES}

1. A. amazonense encontra-se associado a Brachiaria brizantha, B. decumbens e B. humi dicola, com números variando de $10^{3}-10^{7}$ células $\mathrm{g}^{-1}$ deraízes frescas.

2. Populações destes microrganismos associadas a pastagens de Brachiaria implantadas no ecossistema Cerrados foram influenciadas pelo período do ano.

3. Em pastagens instaladas na região de Mata Atlântica, de maneira geral, maiores números de Azospirillum amazonense foram encontrados na espécie B. humidicola, seguida por B. decumbens e B. brizantha.

4. O perfil de fragmentos de restrição da região 16S DNAr confirmou a identidade dos isolados deA. amazonense que anteriormente haviam sido caracterizados fenoti picamente.

5. Todos os isolados de A. amazonense testados foram capazes de produzir AI A.

\section{AGRADE CIMENTOS}

Ao programa PADCT III/CIAMB, pelo financiamento parcial do projeto, e ao CNPq.

\section{LITERATURA CITADA}

ALVIM, M.J .; BOTREL, M.A.; VERNEQ, R.S. \& SALVATI, J .A. Aplicação de nitrogênio em acessos de Brachiaria. 1. Efeito sobre a produção de matéria seca. Past. Trop., 12:26, 1990.

AUDY, P.; BRAAT, C.A.; SAIDON, G.; HUANG, H.C. \& LATOCHE, A. A rapid and sensitive PCR-Based assay for concurrent detection of bacteria causing common and halo blights in bean seed. Phytopathology, 86:361-366, 1996.

BALDANI, J.I.; POT, B.; KIRCHHOF, G.; FALSEN, E.; BALDANI, V.L.D.; OLIVARES, F.L.; HOSTE, B.; KERSTERS, K.; HARTMANN, A.; GILLIS, M. \& DÖBEREINER, J . Emended description of Herbaspirillum; inclusion of [Pseudomonas] rubrisubalbicans a mild plant pathogen, as Herbaspirillum rubrisubalbicans comb. nov.; and classification of a group of clinical isolates (EF Group1) as Herbaspirillum Species 3. Int. J . Syst. Bacteriol., 46:802810, 1996.

BALDANI, J I. O Ocorrência e caracterização de Azospirillum amazonense em comparação com outras espécies deste gênero, em raízes de milho, sorgo e arroz. Rio de J aneiro, Universidade Federal Rural do Rio deJ aneiro, 1984. 110p. (Tese de Mestrado)

BASHAN, Y. \& HOLGUIN, G. Azospirillum-plant relationships: environmental and physiological advances (1990-1996). Canadian J . Microbiol., 43:103-121, 1997.

BELLONE, C.H.; BELONE, S.C. \& PEDRAZA, R.O. Hydric deficiency and acetylene reduction in sugar-cane roots. In: INTERNATIONAL SYMPOSIUM ON NITROGEN FIXATION WITH NON-LEGUMES, 7., Faisalabad, 1996. Abstracts. Faisalabad, 1996. p125-126.

BODDEY, R.M. \& VICTORIA, R.L. Estimation of biological nitrogen fixation associated with Brachiaria and Paspalum grasses using ${ }^{15} \mathrm{~N}$ labelled organic matter and fertilizer. Plant Soil, 90:256-292, 1986.

BUSSABE, W.O.; MIAZAKI, E.S. \& ANDRADE,D.F. Introdução à análise de agrupamentos. In: SIMPÓSIO NACIONAL DE PROBABILIDADE E ESTATÍSTICA, 9., São Paulo, 1990. Anais. São Paulo, Associação Brasileira de Estatística, 1990. 105p.

COSTA, J .M.T.F. \& RUSHEL, A.P. Seasonal variation in the microbial populations of sugar-cane plants. In: VOSE, P.B. \& RUSHEL, A.P., eds. Associative $\mathrm{N}_{2}$ - fixation. Vol II. São Paulo, University of São Paulo, 1981. p109-118.

CROZIER, A.; ARRUDA, P.; J ASMIM, J.M. \& MONTEIRO, A.M. Analysis of indole-3-acetic and related indoles in culture media from Azospirillum lipoferum and Azospirillum brasilense. Appl. Environ. Microbiol., 54:2833-2837, 1988. 
DAVIDSON, J.L. \& MILTHORPE, F.L Leaf growth of Dactylis glomerata L. following defoliation. Ann. Bot., 30:173-184, 1966.

DECKHIL, S.B.; CAHILL, M.; STACKBRANDT, E. \& SLY, L.I. Transfer of Conglomerans Iargomobilis subs. largomobilis to the genus Azospirillum as Azospirillum largomobile comb. nov. and elevation of Conglomeromonas largomobilis subs. parooensis to the new type species of Conglomeromonas, Conglomeromonas parooensis sp. nov. Syst. Appl. Microbiol., 20:72-77, 1997.

DÖBEREINER, J . History and new perspective of diazotrophs in association with non-leguminous plants. Symbiosis, 13:1-13, 1992.

DÖBEREINER, J. Plant genotype effects on nitrogen fixation in grasses. In: MUHAMMED, A.; AKSEL, R. \& BORSTEL, R.C., eds. Genetic diversity in plants, I taguaí, EMBRAPA UEPAE, 1977. p.325-334.

DÖBEREINER, J .; BALDANI, V.L.D. \& BALDANI, J I. . Como isolar e identificar bactérias diazotróficas de plantas não leguminosas. Brasília, EMBRAPA-SPI, Itaguaí, EMBRAPA-CNPAB, 1995. 60p.

FERREIRA, E.; RESENDE, A.S.; ALVES, B.J.R.; BODDEY, R.M. \& URQUIAGA, S. Destino do ${ }^{15} \mathrm{~N}$-urina bovina aplicado na superfície de um solo Podzólico descoberto, ou sob cultura de Brachiaria brizantha cv. Marandu. In: CONGRESSO ANUAL DA SOCIEDADE BRASILEIRA DE ZOOTECNIA, 32., Brasília, 1995. Anais. Brasília, Sociedade Brasileira de Zootecnia, 1995. p.109-110.

FERREIRA，E.; REZENDE，C.P.; GALINDO， L.L.G.; RESENDE, A.S.; TARRÉ, R.M.; MACEDO, R.O.; OLIVEIRA, O.C.; ALVES, B.J.R.; URQUIAGA, S. \& BODDEY, R.M. Recuperação do nitrogênio da urina bovina pela pastagem de Brachiaria humidicola (Rendle) Schweickt cultivada no sul da Bahia. In: REUNIÓN LATINOAMERICANA DE PRODUCCION ANIMAL, 17; CONGRESO URUGUAYO DE PRODUCCION ANIMAL, 3., Montevideo, 2000. Anais. Montevideo, 2000. CD-ROM

HOLLAND, J.N.; CHENG, W. \& CROSSLEY JR., D.A. Herbivore-induced changes in plant carbon allocation: assessment of bellow-ground C fluxes using carbon-14. Oecologia, 107:87-94, 1996.

ITZIGSOHN, R.; BURDMAN, S.; OKON, Y.; ZAADY, E.; YONATAN, R. \& PEREVOLOTSKY, A. Plant-growth promotion in natural pastures by inoculation with Azospirillum brasilense under suboptimal growth conditions. Arid Soil Res. Rehab., 13:151-158, 2000.

KRAFFCZYK, I.; TROLLDENIER, G. \& BERINGER, H. Soluble root exudates of maize: influence of potassium supply and rhizosphere micro-organisms. Soil Biol. Biochem., 16:315-322, 1984.

LOUREIRO, M.F. \& BODDEY, R.M. Balanço de nitrogênio em quatro gramineas do gênero Brachiaria. Pesq. Agropec. Bras., 23:1343-1353, 1988.

MAGALHÃES, F.M.M.; BALDANI, J.I.; SOUTO, S.M.; KUYKENDALL, J.R.; DÖBEREINER, J. A new acidtolerant Azospirillum species. An. Academia Bras. Ci., 55:417-430, 1983.
MAGALHAES, F.M.M. \& DÖBEREINER, J. Occurrence of Azospirillum amazonense in some Amazonian (Brazil) ecosystems. R. Microbiol., 15:246-252, 1984.

MAGALHÃES, F.M.M.; BALDANI, J.I.; SOUTO, S.M.; KUYKENDALL, J.R.; DÖBEREINER, J . A new acidtolerant Azospirillum species. An. Acad. Bras. Ci., 55:417430, 1983.

MASCARUA-ESPARZA, M.A.; VILLA-GONZALLEZ, R. \& CABALLERO-MELADO, J. Acetylene reduction and indolacetic acid production by Azospirillum isolates from Cactaceous plants. Plant Soil, 106:91-95, 1988.

MONZÓN DE ASCONEGUI, M.A. \& SIROLLI, N.S. Presencia de Azospirillum amazonense y micorrizas vesículoarbusculares en rizósfera de gramíneas de Corrientes (Argentina). In: CONGRESO ARGENTINO DE MICROBIOLOGÍA, 4., Buenos Aires, 1985. (Resumen, A49)

NEYRA, C.A. \& DÖBEREINER, J . Nitrogen fixation in grasses. Adv. Agron.., 29:1-38, 1977.

OKON, Y. \& VANDERLEYDEN, J . Root-associated Azospirillum species can stimulate plants. ASM News, 63:364-370, 1997.

OLIVEIRA, O.C.; OLIVEIRA, I.P.; FERREIRA, E.; ALVES, B.J.R.; CADISCH, G.; MIRANDA, C.H.B.; VILELA, L.; BODDEY, R.M. \& URQUIAGA, S. A baixa disponibilidade de nutrientes do solo como uma causa potencial da degradação de pastagens no cerrado brasileiro. In: SIMPÓSIO NACIONAL DE RECUPERAÇÃO DE ÁREAS DEGRADADAS, 3., Ouro Preto, 1997. Anais. Ouro Preto, 1997. p.110-117.

RADWAN, T. EL-SAYED EL-DESOK. Improvement of quality of some crop plants by applying new concepts in biotechnology with Azospirillum and Herbaspirillum spp. Cairo, Cairo University, 1999. 201p. (Tese de Doutorado)

REIS J r., F.B.; REIS, V.M.; SILVA, L.G. \& DÖBEREINER, J . Levantamento e quantificação de bactérias diazotróficas em diferentes genótipos de cana-de-açúcar (Saccharum spp.). Pesq. Agropec. Bras., 35:985-994, 2000.

RODRIGUES NETO, J .; MALAVOLTA J r., V.A. \& VICTOR, O. Meio simples para o isolamento e cultivo de Xanthomonas campestris pv. Citri Tipo B. Summa Phytopatol., 12:16, 1986.

ROHLF, F.J . NTSYS-pc numerical taxonomy and multivariate analysis system, Version 2.1, User guide. New York, State University of New York, Stony Brook, 2000. 37p.

RUESS, R.W. \& MCNAUGHTON, S.J. Grazing and the dynamics of nutrient and energy regulated microbial process in the Serengeti. Oikos, 49:101-110, 1987.

SARWAR, M. \& KREMER, R.J . Determination of bacterially derived auxins using a microplate method. Lett. Appl. Microbiol., 20:282-285, 1995.

SOUTO, S.M. Variação estacional da fixação de $\mathrm{N}_{2}$ e denitrificação em gramíneas forrageiras tropicais. Rio de J aneiro, Universidade Federal Rural do Rio de J aneiro, 1982. 268p. 
TARRAND, J J .; KRIEG, N.R.; DÖBEREINER, J . A taxonomic study of Spirillum lipoferum group, with descriptions of a new genus, Azospirillum gen-nov and two species, Azospirillm lipoferum (Beijerinck) comb. nov. and Azospirillum brasilense sp. nov. Can. J . Microbiol., 24:967980, 1978.
YOUNG, J .P.W.; DOWNER, H.L. \& EARDLY, B.D. Philogeny of phototrophic Rhizobium strain BTAil by polymerase chain reaction-based sequencing of a $16 \mathrm{~S}$ rRNA segment. J. Bacteriol., 173:2271-2277, 1991. 